\title{
Meningioma en Plaque: Experience with 22 Cases
}

\author{
MOHAMMED M. ADAWI, M.D.; MAHMOUD M. WAHDAN, M.D. and RAMY A. TEAMA, M.D. \\ The Department of Neurosurgery, Faculty of Medicine, Benha University
}

\begin{abstract}
Background: Sphenoid wing meningioma en plaque is a unique subtype of intracranial meningiomas, known as intra osseous meningiomas that specifically grow at the base of the anterior and middle cranial fossa, extending to the sphenoid wing and orbit and associated with a significant hyperostosis. They result in neurosurgical complications by direct pressure of nearby cranial nerves, cavernous sinus and carotid artery.

Aim of Study: Present our series of Sphenoid wing meningioma en plaque and to try to conclude the best surgical options and promising results.

Patients and Methods: Retrospective analysis for our records regarding 22 patients with radiologically and pathologically proven en plaque meningioma from Jan 2016 to Nov 2019. All patients underwent complete neurological examination with detailed ophthalmic examination was performed. We adopted the pterional approach with its modification for all surgeries. Post operative CT scan was performed to asses degree of excision and possible recurrence.
\end{abstract}

Results: Mean age was 42 years 21 were females and 1 male. The most common presenting symptom was proptosis in $20(93 \%)$ patients and also 6 patients presented with visual affection (27\%). 7 patients complained of peri-orbital pain. 5 patients observed solid swelling over the Temple region We could remove the tumors in most of cases totally Up to grade II on Simpson scale. In 5 out of 22 cases, the resection was subtotal. Improved Proptosis in 17 out of 22 patients post operative. Adjuvant radiation therapy was performed in 5 patients. After a mean follow-up of 24 monthes, 4 out of 22 patients presented by tumor recurrence $(18,2 \%)$ the recurrences were mainly in the areas around the superior orbital fissure due to our inability to resect the tumor completely for fear of complications and exposed to another course of radiotherapy, No patient presented recurrence after radiation therapy.

Conclusion: Early diagnosis, prompt surgical intervention with resection of all invaded bone as possible are key factors in improving outcome of spheno-orbital meningioma en plaque. Regular follow-up is mandatory as some cases may have unpredictable behavior.

Key Words: Meningioma En plaque - Hyperostosis - Proptosis.

Correspondence to: Dr. Mohammed M. Adawi, The Department of Neurosurgery, Faculty of Medicine, Benha University

\section{Introduction}

SPHENOID wing meningioma en plaque is a unique subtype of intracranial meningiomas, knownas intraosseusmeningiomas that specifically growat the base of the anterior and middle cranial fossa, extending to the sphenoid wing and orbit [1].This tumor has carpet-like, soft tissue structure that invades the dura causing markedhyperostosis [2]. These tumors may sometimes invade the cavernous sinus making total excision impossible, so these tumors have high recurrence rate and postoperative complications [3]. En plaque meningiomas accounts for $2-9 \%$ of all meningiomas [4].

Theories regarding the cause of hyperostosis include vascular disturbances, irritation of bone without actual invasion, previous trauma, bone production by tumor cells, or osteoblastic stimulation of normal bone. Currently, the most widely accepted theory is that this bone growth is actually bone invasion by tumor cells [5].

They result in neurosurgical complications by direct pressure of nearby cranial nerves, cavernous sinus and carotidartery [6,7]. Because of massive bone involvement, differential diagnosis should include fibrous dysplasia, osteoma, osteoblastic metastasis, Paget's disease, hyperostosis frontalisinterna, erythroid hyperplasia, and sarcoidosis [8] This descriptive study aims at sharing our experience in management of spheno-orbital meningioma en plaque and evaluating the outcome.

\section{Patients and Methods}

This retrospective study was conducted at Neurosurgery Department at Benha University Hospitals in the period from January 2016 to November 2019 so as to allow a minimum follow-up period of 6 months for the last case enrolled in the study. 
The study included 22 patients with radiologically and pathologically proven en plaque meningioma. All enrolled patients underwent detailed history taking including demographic data for age and gender, date of presentation, presenting symptoms of headache, neurological symptoms, visual symptoms, and cosmetic disfigurement. Also, history included inquiries about the presence and duration of any comrbidity as hypertension and diabetes mellitus.

The severity of headache was evaluated using the 11-point Numeric Rating Scale (NRS) 11 for assessment of pain intensity with numbers from 0 to 10 where 0 indicates no pain and 10 indicates worst pain imaginable [2].

All patients underwent complete neurological examination for cranial nerve deficits or associated neurological diseases. Detailed ophthalmic examination was performed, including visual acuity, ocular motility examination, pupil evaluation, fundus examination.

Evaluation of degree of proptosis was performed on $\mathrm{CT}$ axial sections or axial MRI passing through the optic nerve and lens [3]:

- Grade 1 (mild): The posterior eye segment is located posterior to the inter-zygomatic line.

- Grade 2 (moderate): The inter-zygomatic line is tangent to posterior sclera margin.

- Grade 3: The posterior eye segment is located anterior to the inter-zygomatic line.

All cases performed brain computed tomography (CT) with bone window in all planes and magnetic resonance imaging (MRI) scans. Axial and coronal CT bone window scans were very helpful for visualization of the hyperostosis. Typical characters on CT films, were significant hyperostosis and thickening of the sphenoid wing and to some extent the squamous temporal bone, lateral orbital wall, the roof orbit and the sphenoid bony structures including the sphenoid sinus. Soft-tissue component of the tumor was spongy in nature with many vacuolated areas.

On MRI, the lesions were hypointense or isointense in T1, in T2 the tumor was mild hyperintense. Markedly enhanced with Gadolinium as a character of meningiomas. Hyperostotic bone showed no enhancement after Gadolinium.

\section{Surgical approach:}

We adopted the pterional approach with its modification in 21 cases. In the last case which was calvarial we excised the involved part of the skull and replaced it by acrylic cranioplasty (As shown in illustrative cases).

We performed resection of the infiltrated osseous tissue as evident on the bone window of CT. So, we reached the apex of the orbit and opened the optic foramen in only 4 cases. Bony resection was performed using small cutting burr, alternating with small Kerrisson rongeur with thin foot plate which is more preferable in de-roofing the optic foramen.

We neither reconstructed the lateral orbital wall nor the orbital roof with no significant postoperative sequel. The craniotomy flaps were infiltrated in 13 cases and were replaced by acrylic cranioplasty. Soft tissue component were shaved from the dura with thorough cauterization of the involved dura. The temporalis muscle was infiltrated in two cases, and the affected part was excised with safety margin. We had recurrence in 2 cases involving mainly the soft tissue component; one of them had significant extension in the cavernous sinus. Both cases were accepted for Gamma-knife radiosurgery.

\section{Illustrative cases:}

Fig. (1): A 45 years old lady presented with long history of headache associated with left facial pain, few months ago she noticed protrusion of her left eye. After ophthalmological consultation she was referred to us with a report declaring normal fundus and visual acuity, and no restriction of extra-ocular muscle motility. CT brain with bone window, and MRI brain with contrast were performed (Fig. 1). She underwent surgical excision, craniotomy flap was repositioned. The postoperative course was uneventful, and she was doing well in follow-up visits (Fig. 1).

Fig. (2): A fifty-eight years old female presented with severe proptosis and lid swelling, MRI brain with contrast revealed sphenoid wing meningioma with intra-osseous (en plaque) component, intraorbital and extra-cranial extension. Patient underwent tumor excision with resection of infiltrated bone of the roof orbit, lateral orbital wall, and infiltrated part of temporalis muscle. The craniotomy flap wasn't repositioned due to dense invasion, and acrylic cranioplasty was done. Pathology revealed grade I transitional meningioma (Fig. 2). 

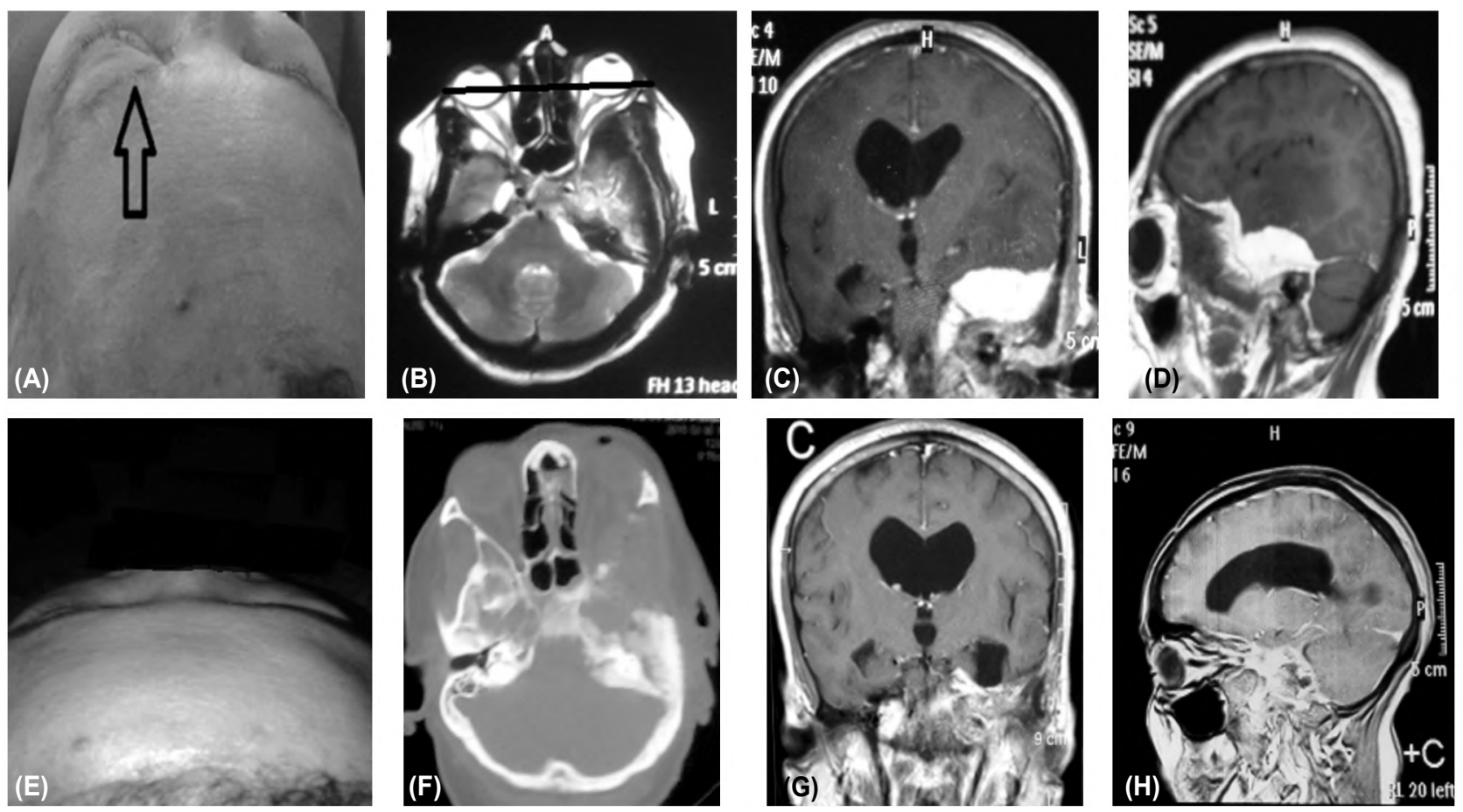

Fig. (1) (A-H): A- Pre-operative image of the patient showing proptosis of the left eye "black arrow". B-MRI brain T2WI axial view through the level of optic nerve and lens, the interzygomatic line is drawn to demonstrate grade 1proptosis of the lefteye, the hyperostotic bone is well appearant. C- Coronal MRIwith contrast showing tumor and dural enhancement. D- Sagittal MRI with contrast showing tumor and dural enhancement, the hyperostotic bone appearing hypointense and non-enhancing. E- Post-operative view of the patient showing some improvement of proptosis (with permission). F- Axial CT, bone window showing resection of the infiltrated bone. G- Coronal MRI with contrast showing adequate tumor excision. H- Sagittal MRI with contrast at the level of optic nerve revealing absence of enhancing tissue.
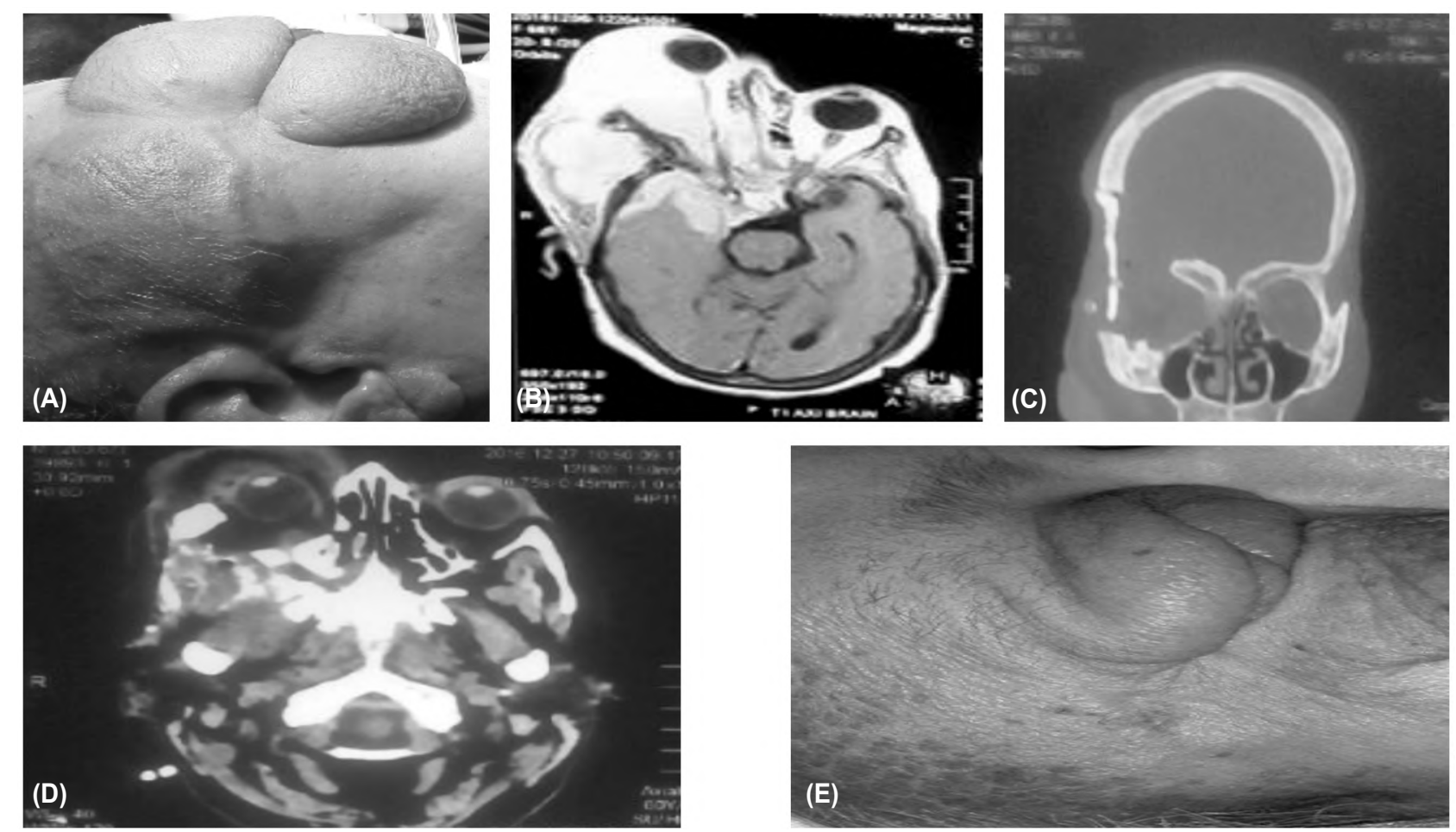

Fig. (2) (A-E): A- Lateral view of the patient with severe proptosis, marked lid swelling and ectropion, and swelling over the right temporal region. B- Axial MRI brain with contrast showing grade 3 proptosis, intra-orbital and extra-cranial tumor extension. C- Coronal CT bone window showing the extent of bone resection and evidence of acrylic cranioplasty. D- Axial CT brain at the level of the lens revealing improvement of proptosis. E- Lateral view of the patient post-operatively. 
Fig. (3): A 42 years old presented with swelling over the posterior part of the frontal bone, CT brain with bone window revealed the frontal mass with insignificant bilateral infiltration of the lesser wing of sphenoid, MRI brain with contrast showed bilateral enhancement of the dura underlying the sphenoid ridge. Surgical excision of the frontal mass was performed followed by acrylic cranioplasty. Pathology revealed intra-osseous grade I transitional meningioma. Conservative treatment of the sphenoid wing en plaque component was decided, and the lesion was stable on follow-up MRI brain with contrast at 3, and 6 months visits (Fig. 3). The patient was scheduled for regular follow-up.

Fig. (4): A 35 years old female presented with headache and proptosis of her right eye. CT brain and MRI brain with contrast revealed sphenoorbital meningioma en plaque (Fig. 4-a,b). Surgical excision of the tumor and acrylic cranioplasty were done (Fig. 5-c). Nine months later the patient noticed recurrence of her right eye proptosis and developed mild left eye proptosis, MRI brain with contrast revealed small area of enhancement extending to the right cavernous sinus and left cavernous sinus meningioma (Fig. 5-d). Patient were accepted for a session of Gamma knife radiosurgery. After fourteen months patient came to followup reporting a history of progressive bilateral proptosis and gradual diminution of vision down to hand movement with restricted ocular motility, MRI brain with contrast showed bilateral sphenoorbital and cavernous sinus meningiomas (Fig. 5ej).
(A)
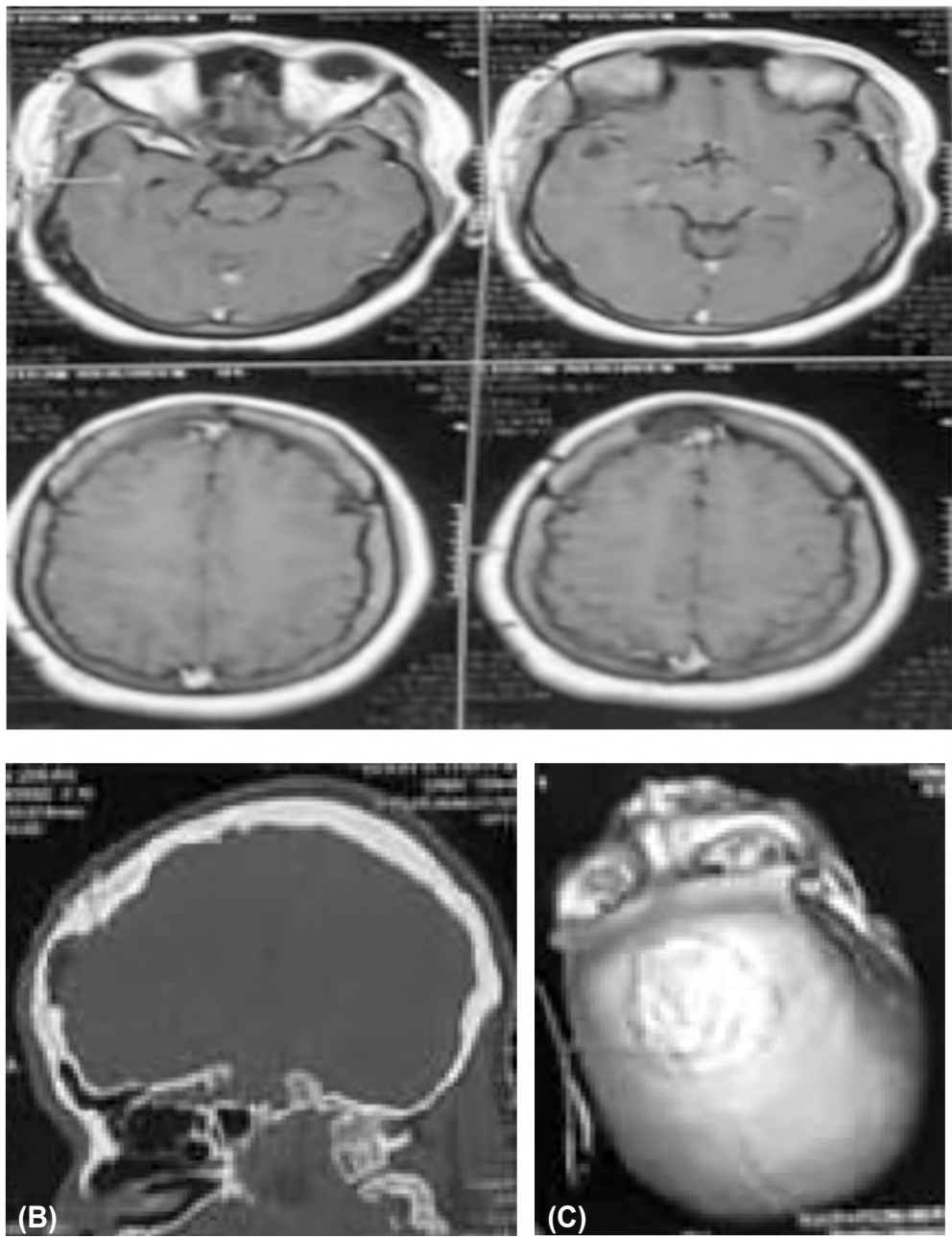
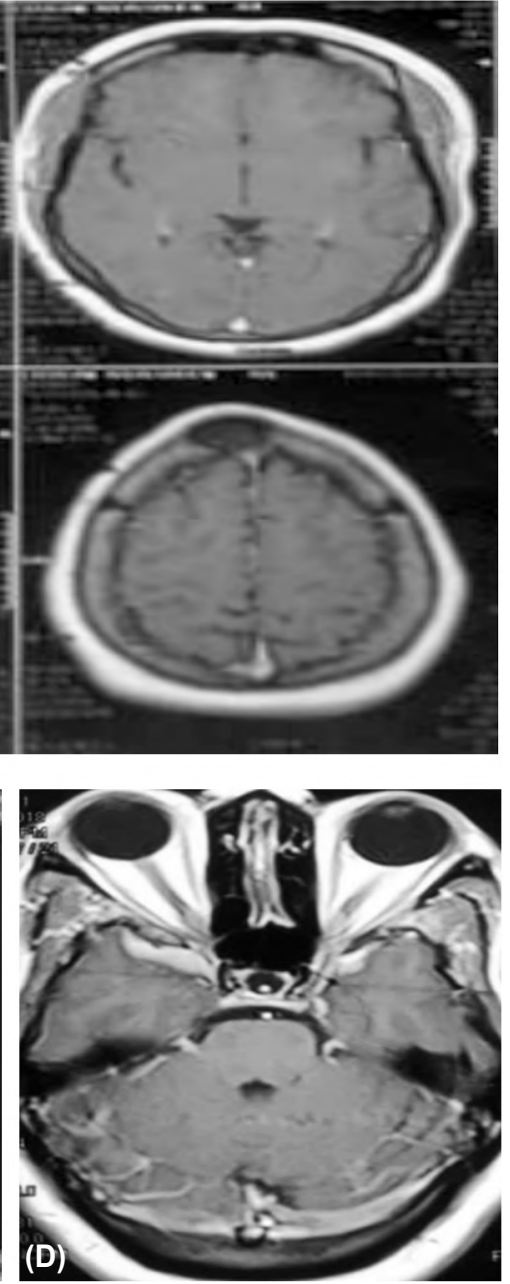

Fig. (3) (A-D): A- Axial MRI with contrast showing full thickness skull mass in the frontal bone associated en plaque component in both lesser wing of sphenoid with intense enhancement of the underlying dura. B- Sagittal CT bone window, C- 3D CT revealing tumor excision and acrylic cranioplasty. D- Follow-up axial MRI with contrast after 6 months showing stationary course of sphenoid wing meningioma, no proptosis. 

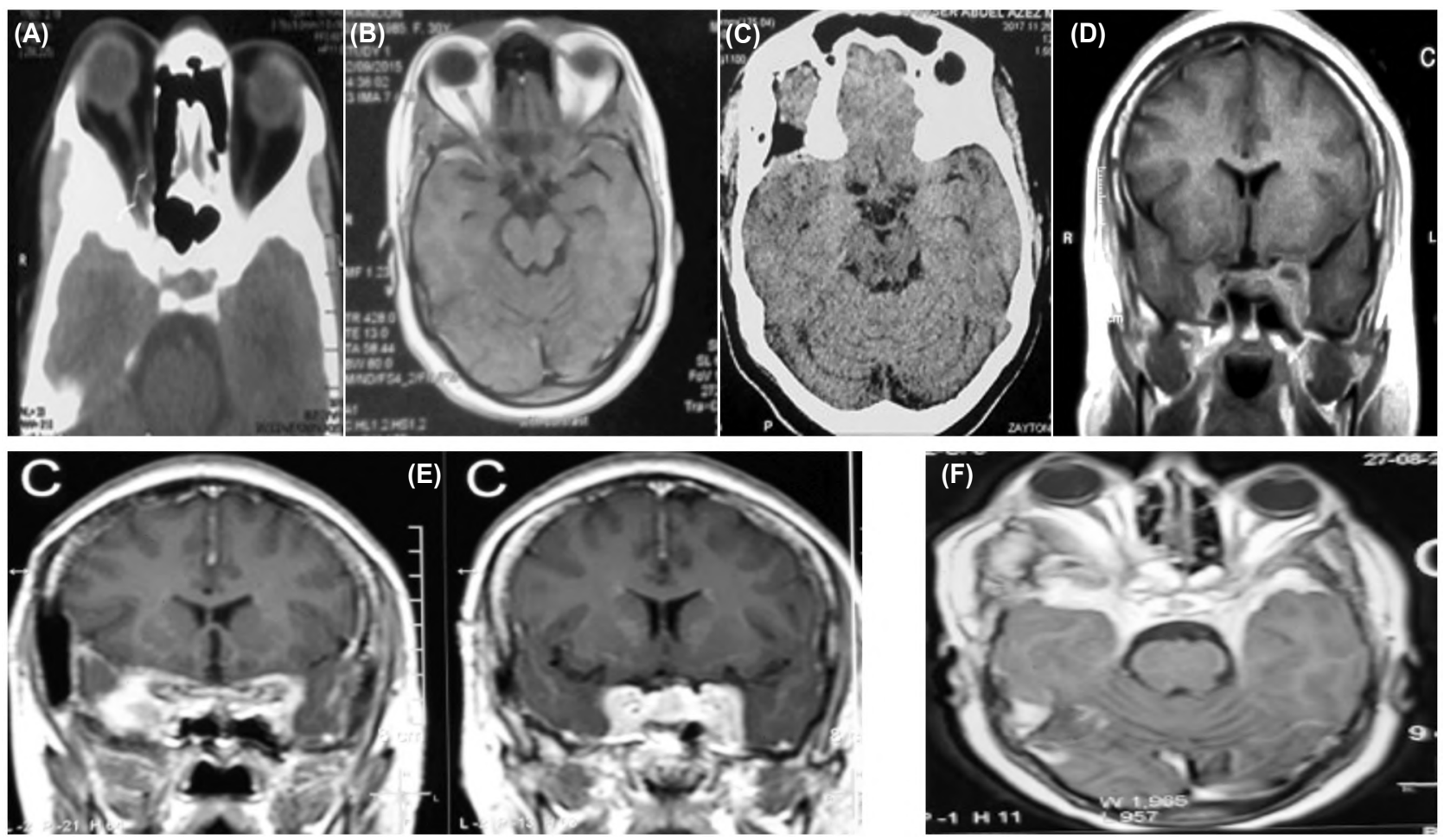

Fig. 4 (A-F): A- CT brain showing the right intra-ossous spheno-orbital meningioma, B- MRI brain with contrast showing dural enhancement, C- Post-operative CT brain, D- Coronal MRI with contrast showing recurrence of the dural enhancing lesion with extension to the ipsilateral cavernous sinus, left cavernous sinus meningioma is readily apparent, E- Coronal MRI with contrast showing bilateral cavernous sinus meningioma, F- Axial MRI brain with contrast bilateral spheno-orbital meningioma.

Fig. (5): A 47 years old female presented with proptosis and diminished vision of her right eye, MRI brain revealed right spheno-orbital meningioma (Fig.6-a). Surgery was performed and the patient developed transient conjuctival congestion and lid edema resolved over few weeks, but visual acuity remained as pre-operative (Fig. 6-b).

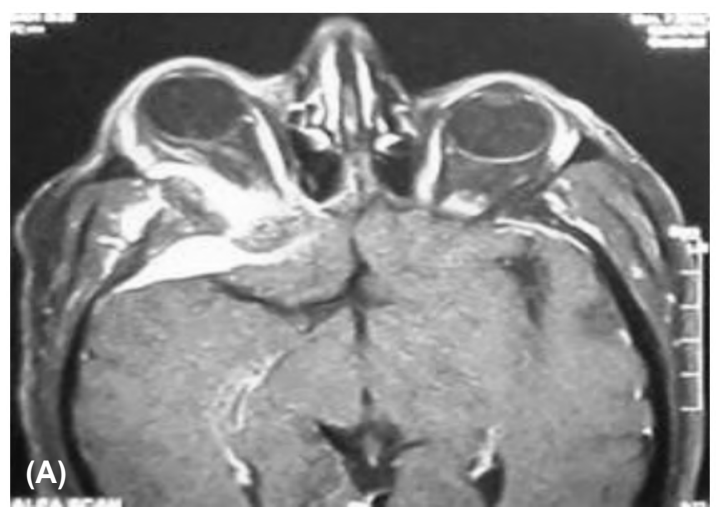

Fig. (6): A 45 years old female presented with right proptosis, CT brain and MRI brain revealed right spheno-orbital meningioma en plaque (Fig. 7-a-c), surgery was done (Fig. 7d) with satisfactory post-operative course (Fig. 7-e,f).

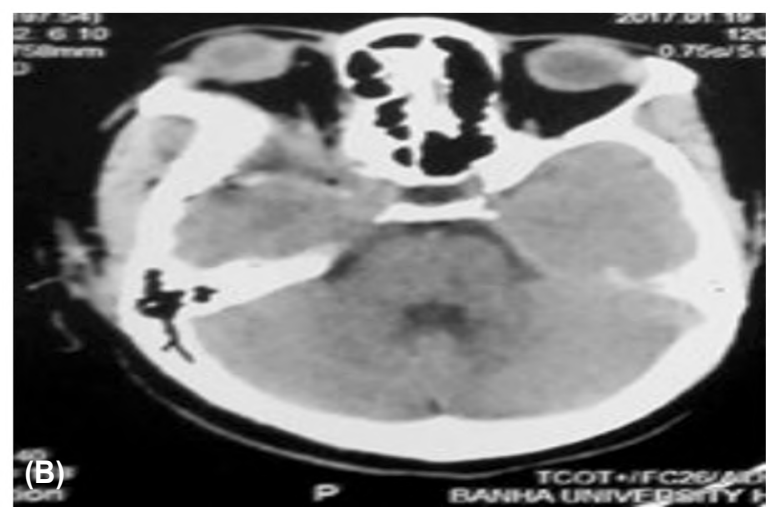

Fig. 5 (A-B): A - Axial MRI brain with contrast showing right spheno-orbital meningioma. B - Post-operative CT brain showing adequate decompression involving deroofing the optic canal. 

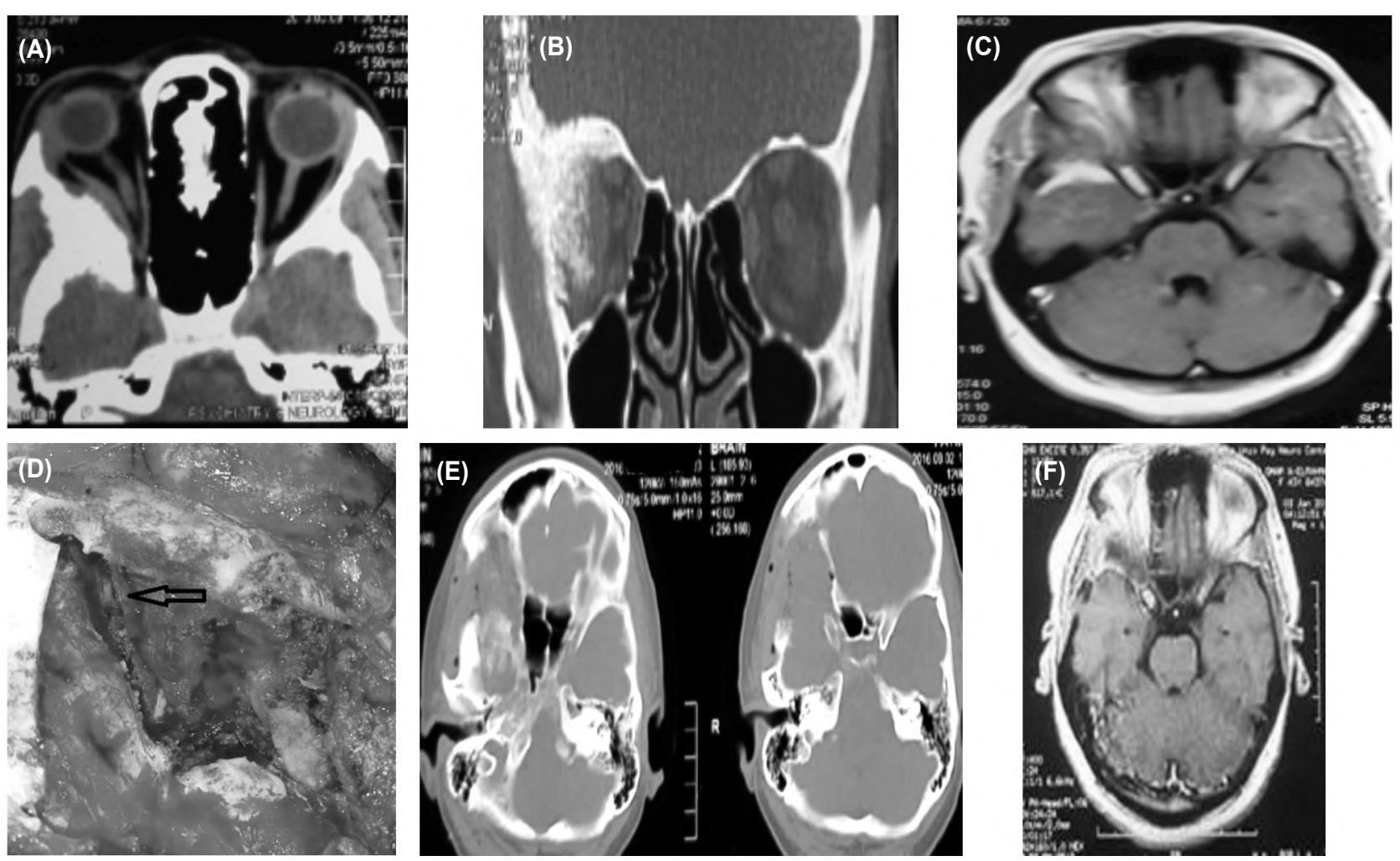

Fig.6 (A-F): A- Axial CT brain showing tumor invasion. B- Coronal CT bone window revealing intra-osseous tumor in the roof and lateral orbital wall. C- Axial MRI with contrast showing enhancing tumor tissue. D- Intra-operative view during resection of the orbital roof. E- Post-operative axial CT bone window demonstrating extent of bony resection of the roof and lateral orbital wall. FFollow-up MRI brain after 3 months proving absence of any enhancing tumor tissue.

\section{Results}

Twenty two patients with en plaque meningiomas were operated, 21 were females and 1 male. The mean age at the time of surgery was 42 years (range: 33-57 years). The most common presenting symptom was proptosis in 21 (93\%) (Rt. 13, Lt. 7, bilat. 1) (1 severe "RT", 2 moderate "RT", 18 mild) and also 6 patients presented with visual affection $(27 \%) 2$ of them improved after surgery while 4 patients still have the same complaint initially but 1 of them deteriorated due to tumor recurrence and developed restricted ocular motility. 7 patients complained of peri-orbital pain (Table 1). 5 patients observed lateral elevation and solid swelling over the Temple region.

Headache experienced in 16 patients before surgery which improved in all cases with variable degrees of improvement due to removed mass and corrected proptosis and visual symptoms. 3 cases presented by Diplopia (restricted ocular motility) which improved shortly after surgery in line with improved proptosis and decompressed superior orbital fissure.
Table (1): Preoperative complaints.

\begin{tabular}{ll}
\hline Complaint & No. \\
\hline Eye Protrusion (Proptosis) & 21 \\
Temple Swelling and/or pain & 5 \\
Visual Affection & 6 \\
Diplopia & 3 \\
Ocular pain & 16 \\
Trigeminal Neuralgia & 3 \\
\hline
\end{tabular}

The greater wing of sphenoid was thickened in 13 patients, the pterygoid process was invaded. The dural components were located in the anterior region of the temporal fossa in most of patients, six patients presented extension into the orbit, and seven patients with cavernous sinus infiltration.

We could remove the tumors in most of cases totally Up to grade II on Simpson scale. In 5 out of 22 cases, the resection was subtotal. Reconstruction cranioplasty was done using Acrylic synthetic grafts that were tailored according to bone defect created by the removed infiltrated bone. All except one tumour specimens that were sent to pathological analysis came with a result WHO grade I menin- 
giomaof transitional type. The remaining one was malignant meningioma WHO grade III.

In some patients with tumours deeply invading the bones of middle cranial fossa they experienced a trigeminal Neuralgia mainly V2 distribution due to compression over the foramen oval and surrounding area, these cases improved after surgery and their symptoms disappeared.

Post-operative anemia was recorded in 6 patients due to bleeding from vascular tumors and they needed blood transfusion, The mean hospital stay was 6 days (range from 4-13). Cerebrospinal fluid leak occurred transiently in 7 cases and managed conservatively.

No mortality recorded for our case series but we encountered complications in some cases, we had 3 patients with mild extradural bleedings that were managed conservatively. 2 patients developed diplopia after wide extra dural work in the area of the superior orbital fissure, occulomotor deficit was the cause and those patients had a mild affection of their visual field, they slightly recovered after 2 months follow-up in which they received a low dose steroids (pridnisolone) and Neurotonics (Vit B combinations) for 1 month.

\section{Follow-up:}

Improved Proptosis in 17 out of 22 patients post-operative. They were satisfied by their cosmetic results after surgery while the remaining patients were reassured that the facial disfigurement will not increase as the tumour is removed and the recurrence will be followed strictly by our team. There were 4 cases with Temporal swelling that improved dramatically after surgery in addition to 1 case with Frontal swelling that also improved in line with improved proptosis.

In the cases subtotal removal, we advised the patients to receive Adjuvant radiation therapy and Gamma knife radiosurgery in a specialized center.

The Mean follow-up Period was 24 months (6m-36m), 4 out of 22 patients presented by tumor recurrence $(18,2 \%)$ the recurrences were mainly due to re-growth of the soft tissue component in the areas around the superior orbital fissure due to our inability to resect the tumor completely for fear of complications.

\section{Discussion}

Sphenoid wing en plaque meningiomas are a clinical and pathological subgroup of meningiomas defined by its particular sheet-like dural involve- ment and its disproportionately large bone hyperostosis. Therefore, the diagnosis is determined by this particular growing pattern rather than histological appearance. Meningiomas present a female predominance, with a female: male ratio of approximately $2: 1$. In this particular type of meningiomas this ratio is higher, from $4: 1$ to $7: 1$ in some series [9].

Li et al., performed a study including 37 patients. The main complain was proptosis and visual deficit. The used approach also was the frontotemporal approach. In this study simpson grade III tumor removal was the main surgical result, proptosis was improved in all patients, tumor recurrence occurred in 7 patients 5 of them were subjected to redo surgery, there were also no death during this series. The authors concluded that extensive tumor removal and bony decompression is a must to have good results [2].

In another study performed by Mirone et al., including 71 patients, the most common complaint was proptosis and visual impairment also, total removal was performed in $83 \%$ of cases, tumor recurrence occurred in 6 patients 3 of them had total tumor removal, at the end the authors recommended aggressive tumor removal including aggressive bony work and suitable optic canal decompression to have good outcome [3]

Meixensberger et al., performed a retrospective study including 30 cases of sphenoorbital meningioma that were treated using fronto-temporal approach. The main presenting symptom was visual impairment more than proptosis, total microscopic tumor removal was achieved in $33 \%$ of cases only, clinical improvement occurred in $65 \%$ of cases, recurrence happened in $27 \%$ [7]

Mariniello et al., performed a study including 60 patients with sphenoorbital meningioma, the main presenting clinical manifestation was visual impairment (60\%), the authors classified tumors into groups according to tumor location in the orbit to four groups (supero-lateral (18 cases); inferomedial ( 8 cases); orbital apex (22 cases); diffuse (12 cases).

The authors found that all cases with diminished visual acuity had invasion of the optic canal and no cases with normal visual functions had optic canal invasion. Different approaches were used according to intraorbital tumor location; pterional approach was used in 39 case, orbitozygomatic approach was used in 3 cases and lateral orbitocranial approach was used in the rest of cases. In all cases with optic canal invasion, good decompres- 
sion of the optic canal was a must. Improvement in visual functions was observed in $50 \%$ of cases and was higher in cases with limited involvement of the optic canal [10]

Essa \& hamdan performed a study including 15 cases of sphenooprbital en plaque meningioma with proptosis, total improvement occurred in 10 cases and 5 cases had partial improvement. Also total tumor removal was achieved in 10 cases while subtotal removal removal occurred in 5 cases. The authors Saied that the most important factor to have good outcome is the surgical experience and availability of surgical aids like drill [11].

Heller et al., performed a study to evaluate results of orbital reconstruction after surgical removal of tumors causing proptosis either sphenoied wing meningioma or intraorbitalpathology in addition to cases of enplaque meningioma. Cases of enplaque meningioma were 11 and the total number of cases was 23 . They concluded that the most important factor of success of orbital reconstruction is the absence of superior orbital fissure invasion and that the surgeon during reconstruction of such cases have to reconstruct a larger orbit than the anatomical size [12].

In a series performed by Boarie et al., including 40 cases, total tumor removal was achieved in 56\% of cases, improvement in proptosis was observed in $92.7 \%$ and improved vision was observed in $66.7 \%$ of cases. Gamma knife radiosurgery was used in 22 cases, reconstruction of the orbit was performed using titanium mesh. Residual tumor was present in cases with involvement of superior orbital fissure and cavernous sinus [13] .

Jesus \& Toledo in there series including 6 cases with en plaque meningioma recommended total removal of the involved bone to achieve good results except in cases with invasion of the superior orbital fissure and optic canal in which total removal may be impossible but nerve decompression is a must in these cases to have good results [8].

Sandalcioglu et al., performed a study including 16 cases four of them were recurrent, the main presentation was proptosis, total tumor removal was performed in $69 \%$ of cases, recurrence was observed in 9 case 6 of them were thought to be removed totally 8 of them were subjected to another surgery, tumor recurrence was related to residual tumor left in the orbit or related to cavernous sinus or pterygopalatine fossa to avoid complications by surgical team [14].
Simas \& Faries recommended postoperative radiosurgery for cases with involvement of the superior orbital fissure (5 cases) or cavernous sinus ( 6 cases), this study included 18 patients, tumor recurrence was observed in 5 cases 2 of them were subjected to surgery and 3 to postoperative radiosurgery, the authors observed no recurrence in 2 situations, the first after radiosurgery, the second if there is no involvement of the cavernous sinus and superior orbital fissure. The authors recommended not to attempt total surgical removal if there is involvement of superior orbital fissure or cavernous sinus and to do subtotal resection in these cases followed by postoperative radiotherapy that give good results [15].

\section{Conclusion:}

The goal of treatment of spheno-orbital meningioma en plaque should focus on long-term tumor control, reduction of the disease and treatmentrelated morbidity and preservation of quality of life. Early diagnosis, prompt surgical intervention with resection of all invaded bone as possible are key factors in improving outcome of spheno-orbital meningioma en plaque. Regular follow-up is mandatory as some cases may have unpredictable behavior.

\section{References}

1- RINGEL F., CEDZICH C. and SCHRAMM J.: Microsurgical Technique and Results of a Series of 63 SphenoOrbital Meningiomas. Neurosurgery, 60 (4 Suppl 2): 21421; discussion 221-2, 2007.

2- LI Y., SHI J.T., AN Y., ZHANG T., FU J. and ZHANG J.: Sphenoid Wing Meningioma en Plaque: Report of 37 Cases. Chin. Med. J. (Engl.), 20; 122 (20): 2423-7, 2009

3- MIRONE G., CHIBBARO S., SCHIABELLO L., TOLA S. and GEORGE B.: En Plaque Sphenoid Wing Meningiomas: Recurrence Factors and Surgical Strategy in a Series of 71 Patients. Neurosurgery, 65 (6 Suppl): 1008; discussion 108-9, 2009.

4- SIMAS N.M. and FARIAS J.P.: Sphenoid wing en plaque meningiomas: Surgical results and recurrence rates. Surg. Neurol. Int., 4: 86, 2013.

5- FLOYD J.R. \& DEMONTE F.: Spheno-Orbital Meningioma. In Hinojosa AQ \& Schmidek H.H. (eds): Schmidek $\&$ Sweet operative neurosurgical techniques: Indications, methods, and results, 6 th edition, Philadelphia, Elsevier Saunders, Vol. I, Ch 37: 444-450.

6- HONIG S., TRANTAKIS C., FRERICH B., STERKER I., KORTMANN R.D. and MEIXENSBERGER J.: Meningiomas Involving the Sphenoid Wing Outcome After Microsurgical Treatment-A Clinical Review of 73 Cases. Cent. Eur. Neurosurg., 71 (4): 189-98, 2010.

7- MEIXENSBERGER J., HONIG S., TRANTAKIS C., FRERICH B., STERKER I. and SCHOBER R.: Sphenoorbital Meningiomas: Outcome After Microsurgical Treat- 
ment: A Clinical Review of 30 Cases. Neurol. Res., 32 (3): 314-25, 2010.

8- JESÚS O.D. and TOLEDO M.M.: Surgical Management of Meningioma en Plaque of the Sphenoid Ridge. Surgical neurology, 55 (5): 265-9, 2001.

9- WIEMELS J., WRENSCH M. and CLAUS E.B.: Epidemiology and etiology of meningioma. J. Neurooncol., 99: 307-14, 2010

10- MARINIELLO G., BONAVOLONTO G., FAUSTOT. and MAIURIA F.: Management of the optic canal invasion and visual outcome in spheno-orbital meningiomas. Clinical Neurology and Neurosurgery, 115 (9): 1615-1620, 2013.

11-ESSA A.A. and HAMDAN A.R2: Sphenoid meningioma enplaque with proptosis: Surgical excision, reconstruction and outcome.Clin. Neurol. Neurosurg., 167: 147-156, 2018.
12- HELLER R., DAVID C. and HEILMAN C.: Orbital Reconstruction for Tumor-Associated Proptosis: Quantitative Analysis of Postoperative Orbital Volume and Final Eye Position. J. Neurosurgery, 8: 1-6, 2019.

13- BOARI N., GAGLIARDI F., SPINA A., BAILO M., FRANZIN A. and MORTINI P.: Management of SphenoOrbital en Plaque Meningiomas: Clinical Outcome in a Consecutive Series of 40 Patients. Br. J. Neurosurg., 27 (1): 84-90, 2013.

14- SANDALCIOGLU I., GASSER T., MOHR C., STOLKE D. and WIEDEMAYER H.: Spheno-orbital Meningiomas: Interdisciplinary Surgical Approach, Resectability and Long-Term Results. J. Craniomaxillofac. Surg., 33 (4): 260-6, 2005.

15- FANG Z.J., ZHANG J.Y. and HE W.M.: CT features of exophthalmos in Chinese subjects with thyroid-associated ophthalmopathy. International Journal of Ophthalmology, 6 (2): 146, 2013.

\section{الأورام السحائية الطبقية خبرة اجراء rr حالة}

مقدمة: الودم السحائى الطبقى فى منطقة الجناح الوتدى هو نوع فريد من الأبرام السحائية داخل الجمجمة، والمعرف باسيم الأودام

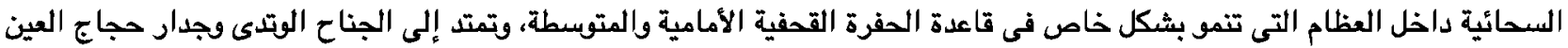
وترتبط بفرط تعظم كبير. تؤدى إلى مضاعفات للأعصاب عن طريق الضغط المباشر للأعصاب المجاودة، والجيوب الكهفية والشريان السباتى.

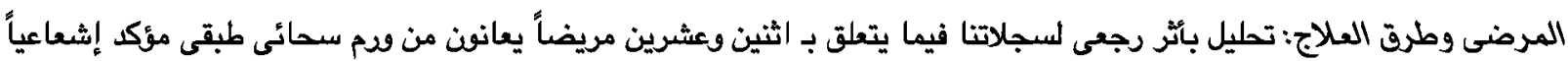

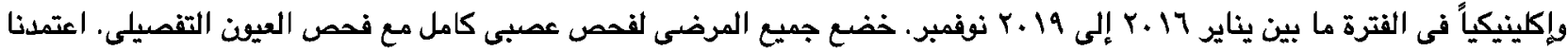

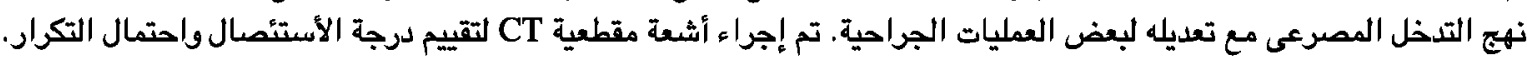

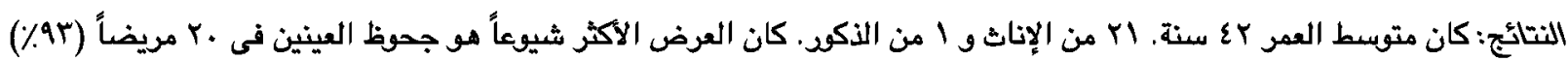

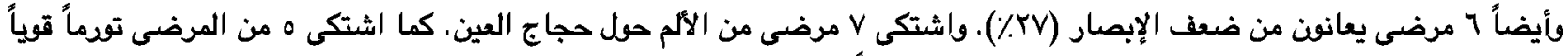

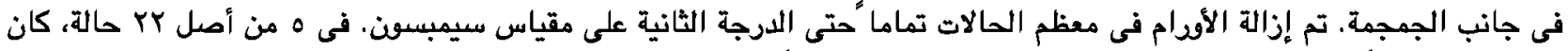

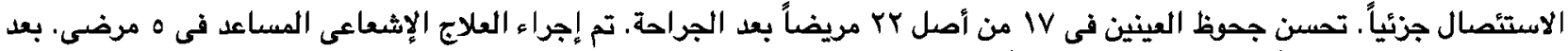

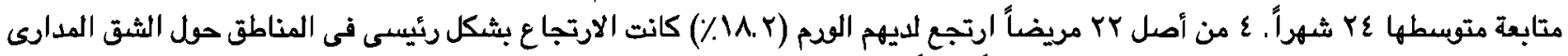

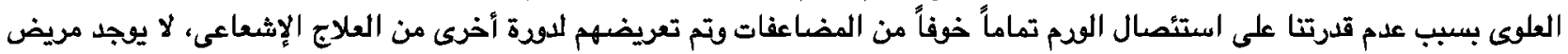

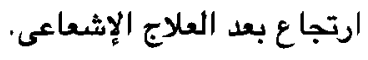

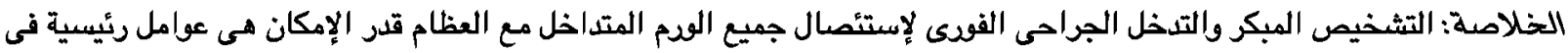

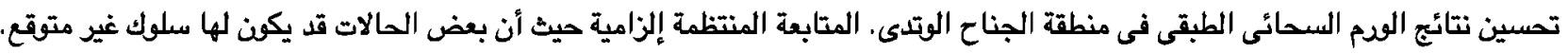

